\title{
Reflexões sobre a dimensão social da música entre os jovens
}

\author{
Maria da Graça Jacintho Setton ${ }^{1}$ \\ Pós-Doutorada pela École des Hautes Études en Sciences Sociales, EHESS, França, \\ e pela Universidade de São Paulo, onde se doutorou em Sociologia e é professora do curso de \\ Pedagogia, Licenciatura e do Programa de Pós-Graduação da FE-USP. Tem experiência na \\ área de Sociologia, com ênfase em Sociologia da Educação e Sociologia da Cultura, atuando \\ principalmente nos seguintes temas: socialização, escola, mídia, religião e família. \\ E-mail: gracaset@usp.br
}

Resumo: O artigo tem como objetivo refletir sobre alguns aspectos da socialização do jovem a partir da linguagem musical. A proposta é destacar a dimensão de integração desta linguagem, bem como sua capacidade de construir identidades. Tomar os produtos culturais, neste caso a música - em sua dimensão social -, é considerá-los como elos entre o indivíduo e a sociedade; é resgatá-los na qualidade de instrumentos de comunicação entre o universo de nossas subjetividades e o universo objetivo da realidade material que nos rodeia. Assim sendo, tem o poder de exercer em nós uma força socializadora. Em outras palavras, considerar a música a partir da perspectiva sociológica é trabalhar o potencial desta linguagem na construção e mediação de códigos e significados de um coletivo e seu poder de constituição de nossa subjetividade.

Palavras-chave: música, comunicação, socialização, jovem.
Abstract: The purpose of this article is to reflect upon some aspects of the youngster socialization coming from the musical language. The proposal is to highlight the integration dimension of this language and its capacity in constructing identities. To take the cultural products, the music in this case, in their social dimension it is to consider their liaison links between the individual and the society; it is to redeem them in their quality of communication instruments between the universe of ours subjectivities and the objective reality that encircle us. Thus, the music has a power of a socialization force. In others words, to take the music from a sociological perspective it is to elucidate the potential of this language in the construction and mediation of the codes and the meanings of a collective and its power to compose our subjectivity.

Keywords: music, communication, socialization, young.
A intenção de analisar a dimensão social da música traduz uma oportunidade de exercitar o que Wright Mills² denominou imaginação sociológica. Ou seja, a sensibilidade de esclarecer as relações de sentido entre um fato social, no caso aqui a música, e suas possíveis influências nas ações individuais. Na realidade, o desafio é fazer uma reflexão sobre a experiência de ser jovem a partir da dimensão socializadora da música.
Recebido: 01.02 .2008

Aprovado: 01.07 .2008

1. Disponível em: $<$ http://lattes.cnpq.br/ 4029283857044455>

2. MILLS, W. A imaginação sociológica. Rio de Janeiro: Zahar, 1965. 
3. FORACCHI, M. A juventude na sociedade moderna. São Paulo: Livraria Pioneira, 1972; PAIS, J. M. (Org.). Traços e riscos de vida. Lisboa: Âmbar, 2000.

4. MARIZ, C. Comunidades de vida no Espí rito Santo: juventude e religião. Tempo Social Revista de Sociologia da USP, São Paulo, v. 17, n 2, p. 253-274, nov. 2005

5. SPOSITO, M. A sociabilidade juvenil e a rua: novos conflitos e ação coletiva na cidade. Tempo Social, Revista de Sociologia da USP, São Paulo, v. 5. n. 1/2, p. 161-178 1993; ABRAMO, H. Cenas juvenis: punks e darks no espetáculo urbano. São Paulo: Scritta, 1994; DAYRELL, J. A música entra em cena: o rap e o funk na socialização da juventude em Belo Horizonte. Tese (Doutorado do Programa de Pós Graduação) - Faculdade de Educação - USP. São Paulo, 2001. comunicação \& educação • Ano XIV • Número 1 • jan/abr 2009

Grande parte da literatura afirma que a juventude é a fase da vida mais marcada por ambivalências. Foracchi e Pais ${ }^{3}$ são autores que chamam a atenção para a convivência contraditória de elementos de emancipação e subordinação, bem como de resistências ou adesões entre os jovens. Ainda que seja impossível determinar uma única forma de vivenciar a juventude, refletir sobre as tensões e expectativas deste grupo é falar de uma sociedade contemporânea na qual se elaboram vivências, paradoxalmente, muito semelhantes. Liminaridades e instabilidades são características comuns a jovens submetidos a diferentes condicionamentos sociais. É nessa etapa da vida, por vezes muito prolongada, que o sentimento de pertença e de comunhão com seus pares surge como uma das estratégias encontradas para se sentirem mais seguros. Concordando com Mariz ${ }^{4}$, diria que a subjetividade juvenil teria uma afinidade eletiva com experiências coletivistas e comunitárias, estas entendidas como gregárias. Práticas como a dança, a música, a drogadição e o engajamento político, ainda que muito díspares, propiciam o conforto de pertencimento a um grupo. Contudo, neste artigo, discutirei a experiência de ser jovem a partir da dimensão social da música. Uma esfera da cultura muito estimulada pelo mercado cultural, mas que possibilita observar um canal de mediação entre subjetividade e exterioridade do jovem.

A relevância do universo simbólico da juventude, em especial o musical, é destacada por estudiosos como Sposito, Abramo, Dayrell ${ }^{5}$. Segundo estes autores, o mundo cultural aparece como um espaço privilegiado de práticas, representações e rituais no qual os jovens tentam demarcar suas identidades. Apoiando-me em todos eles, irei resgatar a dimensão da música enquanto linguagem, ou seja, enquanto potencial veículo mediador e construtor de realidades objetivas e subjetivas deste grupo.

Explorando a construção de sentido da expressão cultura musical, sentido este objetivado em ritmos, sons e palavras, darei destaque à função que podem cumprir enquanto linguagens. Partindo de uma perspectiva sociológica, encaminharei esta discussão lembrando a contribuição de autores que privilegiaram a importância socializadora da linguagem e sua capacidade de objetivar e construir sentidos.

\section{O POTENCIAL SOCIAL DA MÚSICA}

Para investigar sobre o potencial social da música, é preciso tomá-la, primeiramente, como um fato social, ou seja, como um dado da realidade objetiva, da realidade exterior a todos nós, que tem o poder de agir sobre nossa subjetividade, ou seja, de agir sobre nossa consciência. Trabalhar a dimensão social da música é um caminho também para refletir sobre um tema clássico na sociologia. Qual seja, a relação entre indivíduo e sociedade, que se desenvolve no processo de socialização. Nesse sentido, cabe perguntar, 
como se dá essa articulação? Como se operacionaliza a relação indivíduo e sociedade? $\mathrm{Ou}$, mais especificamente, como a música pode socializar e, consequentemente, como a música pode nos ajudar a falar sobre a difícil tarefa de construir a identidade do jovem de hoje?

Para Pierre Clastres, Peter Berger e Thomas Luckmann ${ }^{6}$, entre outros, tomar os produtos culturais em sua dimensão social é considerá-los como um elo entre o ator e a sociedade; é resgatá-los na qualidade de linguagem, como instrumentos de comunicação entre o universo de nossas subjetividades e o universo objetivo da realidade material que nos rodeia. Têm o poder de exercer em nós uma força socializadora. Em outras palavras, tomar a música a partir da perspectiva sociológica é trabalhar o potencial desta linguagem na construção e mediação de códigos e significados de um coletivo.

Ou seja, pensar a música como elemento de uma cultura é considerá-la capaz de agregar, mas, também, de isolar os indivíduos de seus semelhantes, na medida em que constrói subjetividades. Dizendo de outra forma, como fenômeno social, a música tem a capacidade de articular o indivíduo a um grupo de referência mais imediato; porém, também cumpre outra função: serve como instrumento de diálogo interno, diálogo formador de subjetividades. Na objetivação das letras, ritmos e sons, a mensagem musical pode oferecer material reflexivo para os jovens falarem de si para si mesmos ${ }^{7}$.

\section{O PODER DA LINGUAGEM}

Para Berger e Luckmann, todos nós, ao nascermos, somos submetidos a um acervo de conhecimentos sociais que nos ajudam a conviver e a construir a realidade da vida cotidiana. No entanto, essa convivência e essa construção só são possíveis a partir da interiorização de um sistema de códigos, uma série de sinais gestuais, linguísticos e simbólicos que organizam nosso conhecimento sobre o mundo e estabelecem a forma como temos que constituir nossas relações sociais.

O processo de aquisição desse sistema de sinais se dá em função da nossa capacidade biológica de produzir, compreender e transmitir sentidos numa forma objetivada. Palavras, sons, gestos e imagens, bem como seus respectivos significados, estão objetivados em códigos que todos comungam por uma questão de necessidade prática. Os autores lembram que, para estabelecer relações com nossos semelhantes, é preciso partilhar certos símbolos de entendimento coletivo. Dessa forma, Berger e Luckmann afirmam que a realidade da vida cotidiana só é viável pela objetivação e exteriorização destes códigos. Em outras palavras, a vida cotidiana só se realiza através da linguagem ou sistemas comunicativos, pois é com ela que estabelecemos relações de fato e de sentido com o mundo exterior. A linguagem cumpre, então, a função primordial de comunicação e interação entre os indivíduos e o universo cultural que os cerca.
6. CLASTRES, P. O arco e o cesto. In: A sociedade contra o Estado. São Paulo: Francisco Alves, 1978. p. 71-89; BERGER, P.; LUCKMANN, T. A construção social da realidade. Petrópolis: Vozes. 1983.

7. A esse respeito, ver: GOUVÊA, Ana Regina. Comunicação, educação e mídia. Por um ensino motivador e alegre: estudo de caso da EE Godofredo Furtado. Comunicação \& Educação. São Paulo: CCA-ECA-USP/Paulinas, ano $\mathrm{XI}$, n. 1, jan./abr. 2006. 
Assim, essas objetivações - esses códigos linguísticos, a língua, os gestos e/ou as imagens etc. - servem de índices nos processos de tomada de consciência de todos nós, permitindo ainda que as relações de sentido entre os indivíduos, embora tenham sua origem nas relações face a face, se estendam além disso. Dito com outras palavras, a expressividade humana a partir da linguagem é capaz de objetivar sentidos aqui e agora, mas nos permite também acumular símbolos em uma variedade de formas - livros, CDs, DVDs, imagens etc. - que podemos transmitir para uma posteridade. Nesse sentido, a linguagem objetivada nestes artefatos nos oferece a contínua realização da experiência social em desenvolvimento, bem como nos permite a construção de amplos patrimônios culturais.

Mais especificamente, na qualidade de objetivar os sentidos, a linguagem carrega consigo também a possibilidade de transcender ao imediato. Estabelece pontes entre diferentes zonas dentro da realidade e a integra em uma totalidade dotada de sentido. Portanto, como resultado desta transcendência, a linguagem é capaz de tornar presente uma variedade de objetos que estão espacial, temporal e socialmente distantes. Dito de maneira simples, por meio da linguagem um mundo inteiro pode ser atualizado, pensado e desejado a qualquer momento ${ }^{8}$.

A linguagem constrói, pois, imensos edifícios de representação simbólica que parecem elevar-se sobre a realidade da vida cotidiana como presenças autônomas. Uma vez objetivados estes sistemas simbólicos, passam a ter vida própria. Embora construídos, manejados e utilizados pelos atores sociais, seus produtores agem sobre eles com um poder mágico, quase sobrenatural, pois podem trabalhar com eles como força socializadora, ora coercitiva, ora emancipadora; isto é, estes sistemas simbólicos podem agir sobre seus produtores como força exterior.

No entanto, se, para Berger e Luckmann, a linguagem cumpre a função primordial de comunicação entre indivíduo e sociedade, é preciso salientar que ela também só é capaz disso porque tem uma outra função. A linguagem como mecanismo de objetivação e comunicação com o mundo exterior tem o poder simbólico também de forjar nossa consciência interna. Ou seja, a linguagem é o veículo de construção de nossa subjetividade. Ao interiorizar a realidade objetiva, ao tomar ciência dos códigos sociais, ao tomá-los como nossos, passamos a nos identificar e nos perceber como sujeitos, como individualidades, com características próprias. Passamos a ter consciência sobre a nossa pessoa e sobre a relação que mantemos com os outros que nos cercam. Dessa forma, é possível afirmar que a realidade da vida cotidiana está subjetivamente objetivada em nós, está em nossa consciência.

A sociedade é ao mesmo tempo uma realidade objetiva e subjetiva,

8. BERGER, P.; LUCKMANN, T. A construção social da realidade, cit. porque se constrói sob a mediação da linguagem, que está objetivada em códigos e tem o poder de subjetivar, formar a consciência que temos de nós e dos outros. Ou seja, a sociedade e a relação que mantemos com ela 
Reflexões sobre a dimensão social da música • Maria da Graça J. Setton

devem ser compreendidas a partir de um processo dialético composto de três momentos: exteriorização, objetivação e interiorização de sentidos objetivados pela linguagem ${ }^{9}$.

\section{MAS O QUE TEM A VER A QUESTÃO DA LINGUAGEM COM O MUNDO JOVEM?}

Segundo Abramo ${ }^{10}$, a juventude surge como tema na sociologia em função da sua emergência como problema específico das sociedades modernas. Tratados como delinquentes ou contestadores, os jovens só há pouco tempo passaram a inspirar estudos que mostram suas práticas como criativas e produtoras de expressões artísticas. De certa forma, é compreensível que isso ocorra, pois a juventude marca, na nossa cultura, uma fase tensa do ciclo vital em que os processos de autonomização constituem uma de suas tarefas mais importantes. Ou seja, processos que implicam separações nos sistemas de referência emocional e familiar, bem como novas afirmações práticas e relações no meio social envolvente ${ }^{11}$.

Contudo, neste artigo, a indagação é sobre uma específica maneira de o jovem fazer uso da linguagem musical. Entre todas as esferas, a musical é aquela que está mais presente em suas vidas, sejam eles provenientes ou não de segmentos privilegiados. Independentemente do sexo, do grupo etário ou da classe social, até mesmo de país, a música surge como um fenômeno social, pois consegue agregar, sensibilizar e, sobretudo, construir laços de sociabilidade entre os jovens ${ }^{12}$. E, nessa qualidade, a música surge como um canal mediador entre a experiência de ser jovem e o grupo de referência que o cerca, socializando-o.

Neste artigo são lembradas algumas pesquisas que vêm atestando este fato. Segundo Gomes ${ }^{13}$, em Portugal, o hábito de acionar um aparelho sonoro logo que se chega à casa é partilhado por $80 \%$ dos jovens; estudar ou trabalhar ao som da música é comum para $70 \%$ deles; $57 \%$ dos jovens apenas ouvem a música, e com o volume alto, $66 \%$ deste mesmo grupo. Na França, mais de $80 \%$ dos jovens, entre 15 e 17 anos, escutam em média 125 minutos de rádio por dia; aproximadamente $70 \%$ deles acompanham programas musicais, bem como $72 \%$ ouvem rádio, CDs ou $\mathrm{K} 7$ diariamente $^{14}$. Estatísticas sobre os equipamentos de escuta musical permitem medir também a importância desta prática em suas vidas. Entre os jovens de 15 a 17 anos, $90 \%$ deles têm um leitor de CD, e três quartos dos jovens desta idade escutam música todos os dias. Segundo Pasquier, a música é também o assunto preferido entre os adolescentes de mais de 15 anos $^{15}$.

Sobre o campo de análise que nos interessa, ou seja, o potencial da música de tecer redes de sociabilidade, a experiência portuguesa retratada por Gomes é reveladora. O autor observa que a relação entre gostos musicais e redes de amizade é notadamente visível quando se considera a afinidade
9. Ibid.

10. ABRAMO, H. Cenas juvenis, cit.

11. GAMEIRO, José; DANTAS, Ana. Conclusão. In: PAIS, J. M. (Org.). Traços e riscos de vida, cit.

12. DAYRELL, J. A música entra em cena, cit.

13. GOMES, Rui. Sociografia dos lazeres e práticas culturais dos jovens portugueses. In: PAIS, J. M. Condutas de risco, práticas culturais e atitudes perante o corpo: resultados de um inquérito aos jovens portugueses. Oeiras: Ed. Celta/Instituto Português da Juventude, 2003. p. 123-150.

14. LAGOÜET, G. Les jeunes et les médias em France. L'etat de l'efance (Os jovens e os meios de comunicação: a situação da infância). Paris: Hachete, 2000.

15. PASQUIER, D. Cultures Lycéennes. La tyrannie de la majorité (A cultura dos liceus: a tirania da maioria). Paris: Ed. Autrement, 2005. 
* Ver também CITELLI, Adilson. Comunicação e Educação: a linguagem em movimento. 2. ed. São Paulo: Editora SENAC, 2002. p. 186-190. (N.E.)

16. GOMES, Rui. Sociografia, cit.

17. DAYRELL, J. A música entra em cena, cit.

18. CLASTRES, P. O arco e o cesto. In: A sociedade contra o Estado. São Paulo: Francisco Alves, 1978. p. 71-89. de preferência musical entre amigos próximos. Isto é, exatamente a metade dos jovens avalia o gosto musical dos amigos como bastante próximo ao seu. Se este contingente for somado ao dos jovens que definem as preferências dos amigos como muito parecidas com as suas, pode-se concluir que dois a cada três jovens entendem que a proximidade relacional se traduz positivamente em matéria musical.

No Brasil, segundo o Mapa da Juventude - pesquisa realizada, em 2002, pelo Centro de Estudos da Cultura Contemporânea -, entre os grupos artísticos, a categoria que reúne maior parte dos grupos é de música, isto é, 27\% do total. Ainda sobre laços de convivência, ouvir música e conversar sobre ela com os amigos são práticas comuns em mais da metade dos jovens portugueses*. No que concerne à troca de discos, os jovens de até 17 anos são os que mais realizam tal prática entre si, ou seja, mais da metade desenvolve esta dinâmica; comportamento que sem dúvida reforça laços sociais ${ }^{16}$.

E, por último, o estilo ou o gênero musical é elemento revelador nas práticas juvenis, porque manifesta nos gostos as possíveis afinidades de grupo, as redes de sociabilidade e, sobretudo, fontes e referências identitárias. Concordando com Dayrell ${ }^{17}$, é possível afirmar que os estilos musicais podem servir como elementos mediadores, oferecer recursos reflexivos sobre as condições de vida dos jovens, sobre o processo de construção da realidade em que vivem, bem como estimulá-los na manipulação e na reelaboração do conhecimento formal e informal sobre o mundo. E, nesse sentido, os estilos musicais são capazes de cumprir uma função de integração grupal, de servir como referência de grupo e, portanto, se realizar como instituição identitária.

Mas será que a função da música se reduziria a este papel, de reforçar laços identitários e/ou comunitários? Como compreender o comportamento de inúmeros jovens que a ouvem a sós, em seus quartos, com fones, entre as tarefas domésticas ou escolares, ou até mesmo entre as tarefas do trabalho?

Considerando as observações de Clastres ${ }^{18} \mathrm{em}$ seu clássico texto $O$ arco $e$ o cesto, é possível aproximar a experiência dos jovens com a dos índios estudados por ele. Tanto para aqueles como para os guaiaquis, a música, enquanto linguagem, não se reduziria a uma ação corrente da vida cotidiana, aquela dimensão que permite a troca e a reciprocidade entre os grupos sociais. Ela poderia cumprir uma função complementar.

Seguindo as pistas oferecidas por Clastres, creio que os jovens de hoje são capazes de encontrar na dimensão musical, na apreciação de um estilo ou ritmo musical, no canto ou na escuta solitária em aparelhos sonoros portáveis, ou mesmo no aprendizado de um instrumento, uma estratégia de autoconhecimento. A música para os jovens, como para os guaiaquis, pode ser o momento de um verdadeiro diálogo consigo mesmos. Assim, tomando a linguagem musical em sua dimensão social enquanto instrumento de socialização, via de acesso a um mundo exterior e interior, ou mais, por 
sua natureza e função, pode ilustrar de modo exemplar a relação geral do jovem com a dimensão individual de sua vida.

\section{CONSIDERAÇÕES FINAIS}

Esta reflexão teve como objetivo compreender alguns aspectos da socialização do jovem a partir da linguagem musical. Ou seja, propôs refletir sobre o potencial desta linguagem na construção e mediação de códigos e significados sociais e seu poder de constituição da subjetividade entre os jovens. Tentando compreender o uso lúdico, individual e coletivo desta expressão, apoiamo-nos nas contribuições de autores que partilham um entendimento de que a construção das práticas e dos sentidos da cultura ocorre a partir de um processo dialético composto de três momentos: exteriorização, objetivação e interiorização de sentidos objetivados pela linguagem ${ }^{19}$.

Esses autores ofereceram insights para pensar que, longe de ser apenas distração ou entretenimento, a música poderia representar uma via de interação entre o jovem e o mundo que o rodeia. Mais do que isso, a linguagem musical seria ainda fonte de subjetivação. Chamamos a atenção para o fato de que a linguagem, quando deixa de ser utilizada como meio de comunicação, quando é desviada de seu fim natural, que é a relação com o outro, quando as palavras não se destinam a nenhuma escuta, são elas mesmas seu próprio fim. Transformando-se de sistemas de signos móveis entre emissores e receptores em pura posição de valor para um ego, a linguagem musical não deixa de ser o lugar do sentido. Ao contrário, o sentido subsiste, mas agora desprovido de sua dimensão de comunicação com o exterior. A partir das considerações de Berger, Luckmann e Clastres, pudemos observar que a linguagem musical para os jovens nos remete a uma natureza dupla e essencial da linguagem. Ou seja, ela se manifesta ora em sua função de comunicação, ora em sua função fechada de constituição de um ego ${ }^{20}$.

A prática musical não cumpre apenas o papel de construir a sociabilidade entre os grupos juvenis; como qualquer outra forma de linguagem, pode ser manejada por si mesma, pois não se reduz à função que exerce de comunicação entre os grupos. Não há, portanto, paradoxo no fato de que o mais inconsciente e o mais coletivo da humanidade - a linguagem - possa ser também a consciência mais transparente e a dimensão mais liberada de construção de nossas subjetividades.

Ou seja, os jovens podem utilizar a linguagem musical para se socializar com os outros; contudo, podem também experimentar a partir da música um diálogo interno. A música, enquanto linguagem, na verdade, preencheria a dupla missão de reunir os jovens e de quebrar os laços que os unem ao coletivo. A linguagem musical não é pura e simplesmente um instrumento de comunicação e informação; pode ser vista como meio de subjetivação, de constituição de um ego em transição, veículo que ajudaria no difícil processo de emancipação para a idade adulta.
19. BERGER, P.; LUCKMANN, T. A construção social da realidade, cit.

20. CLASTRES, P. O arco e o cesto, cit. 
comunicação \& educação • Ano XIV • Número 1 • jan/abr 2009

\section{REFERÊNCIAS BIBLIOGRÁFICAS}

ABRAMO, H. Cenas juvenis: punks e darks no espetáculo urbano. São Paulo: Ed. Scritta, 1994.

BERGER, P.; LUCKMANN, T. A construção social da realidade. Petrópolis: Vozes, 1983.

CITELLI, Adilson. Comunicação e Educação: a linguagem em movimento. 2 ed. São Paulo: Editora SENAC, 2002.

CLASTRES, P. O arco e o cesto. In: A sociedade contra o Estado. São Paulo: Francisco Alves, 1978.

DAYRELL, J. A música entra em cena: o rap e o funk na socialização da juventude em Belo Horizonte. Tese (Doutorado no Programa de PósGraduação) - Faculdade de Educação - USP, São Paulo, 2001.

FORACCHI, M. A juventude na sociedade moderna. São Paulo: Livraria Pioneira, 1972.

GAMEIRO, José; DANTAS, Ana. Conclusão. In: PAIS, J. M. (Org.). Traços e riscos de vida. Lisboa: Âmbar, 2000.

GOMES, Rui. Sociografia dos lazeres e práticas culturais dos jovens portugueses. In: PAIS, J. M. Condutas de risco, práticas culturais e atitudes perante o corpo: resultados de um inquérito aos jovens portugueses. Oeiras: Ed. Celta/Instituto Português da Juventude, 2003.

GOUVÊA, Ana Regina. Comunicação, educação e mídia. Por um ensino motivador e alegre: estudo de caso da E. E. Godofredo Furtado. Comunicação \& Educação. São Paulo: CCA-ECA-USP/Paulinas, ano XI, n. 1, jan. /abr. 2006.

LAGOÜET, G. Les jeunes et les médias em France. L'etat de l'efance (Os jovens e os meios de comunicação: a situação da infância). Paris: Hachete, 2000.

MARIZ, C. Comunidades de vida no Espírito Santo: juventude e religião. Tempo Social, Revista de Sociologia da USP, São Paulo, v. 17, n. 2, nov. 2005.

MILLS, W. A imaginação sociológica. Rio de Janeiro: Zahar, 1965.

PAIS, J. M. (Org.). Traços e riscos de vida. Lisboa: Âmbar, 2000.

PASQUIER, D. Cultures Lycéennes: la tyrannie de la majorité (A cultura dos liceus: a tirania da maioria). Paris: Ed. Autrement, 2005.

SPOSITO, M. A sociabilidade juvenil e a rua: novos conflitos e ação coletiva na cidade. Tempo Social, Revista de Sociologia da USP, São Paulo, v. 5. n. 1/2, 1993. 